\title{
Effect of Mo interlayer on magnetic properties of exchange coupled Sm-Co/Fe bilayers
}

\author{
Furrukh Shahzad \\ Centre for Solid State Physics, University of the Punjab, Lahore-54590, Pakistan and \\ School of Physics and Microelectronics, Shandong University, \\ Jinan, Shandong, 250100, People's Republic of China \\ Saadat Anwar Siddiqi \\ Centre for Solid State Physics, University of the Punjab, Lahore-54590, Pakistan
}

\begin{abstract}
Shi-Shen Yan, Xu Jing, Bai Hong-liang, Tang Min-jian, Xing Peng-fei, He Shu-min, and Xu Tong-shuai School of Physics and Microelectronics, Shandong University, Jinan, Shandong, 250100, People's Republic of China
\end{abstract}

(Received on 29 December, 2009)

\begin{abstract}
$\mathrm{Sm}-\mathrm{Co} / \mathrm{Fe}$, hard/soft magnetic bilayers have been fabricated on $70 \mathrm{~nm} \mathrm{Cr}$ buffered $\mathrm{Si}$ (100) substrate by dc and $\mathrm{rf}$ magnetron sputtering and annealed at $525^{\circ} \mathrm{C}$ for $30 \mathrm{~min}$. Very thin Mo layers $(0-0.7 \mathrm{~nm})$ were introduced between Sm-Co and Fe layers. The samples were analyzed by X-Ray Diffraction (XRD) and Alternating Gradient Magnetometer (AGM). All of the samples showed strong exchange coupling between hard and soft magnetic phases. Magnetization, coercivity and energy product $(\mathrm{BH})_{\max }$ suggest a sinusoidal behavior. The energy product was found increased to $45 \%$ for $0.3 \mathrm{~nm}$ Mo interlayer as compared to sample without Mo layer.

Keywords: Sputtering; Nanocomposite; Magnetic measurements; Exchange spring magnets.
\end{abstract}

\section{INTRODUCTION}

Exchange coupled hard and soft magnetic materials are future candidate for permanent magnets. These are nanocomposite materials with higher magnetization. This type of magnets is named as spring exchange magnets. In spring exchange magnets, soft and hard phases are exchange coupled with each other at certain grain sizes which are usually around $10 \mathrm{~nm} \mathrm{[1-3].} \mathrm{In} \mathrm{such} \mathrm{conditions} \mathrm{of} \mathrm{soft} \mathrm{and} \mathrm{hard}$ phases, the hysteresis loop becomes like a single phase magnet. When hard and soft phases are combined with each other with grain sizes greater than the particular size then hysteresis loop shows shoulder in second and forth quadrant i.e. two phase behavior. However for strong exchange coupling between hard and soft phases we get single phase loop [4].

Energy product $(\mathrm{BH})_{\max }$ is key parameter for measuring strength of permanent magnets, in this regard it has been predicted that for exchange coupled soft and hard magnets, energy product can be achieved which is more than double the value of existing permanent magnets [5]. But practically so far, the energy product has not been achieved even half the predicted values. Therefore new approaches are needed to get higher energy product.

Spring exchange magnets have been prepared by mechanical milling [6], melt spinning [1], sputtering [7,8] and by chemical method [9]. Among these techniques sputtering has advantage to have well control on the thickness of soft and hard phases because layer thickness is basic parameter to get strong exchange coupling between the two phases.

In 1986 Grunberg et al. [10] observed that by inserting non magnetic layers between two soft ferromagnetic layers, the magnetization show sinusoidal behavior with about $1 \mathrm{~nm}$ period. After this discovery, same oscillatory behavior was observed by some other groups with different magnetic and non magnetic layers [11-15]. So it is interesting to observe the variation of energy product of soft/hard nanocomposite magnets within the period of oscillation (less than $1 \mathrm{~nm}$ ) by inserting non-magnetic layer at interface of soft and hard phase. In present work we observed rise in energy product by changing thickness of Mo interlayer between exchange coupled Sm-Co hard and Fe soft phase layers. We did this work with deposition of layers at elevated temperature and with post annealing separately. In this paper, we report the enhancement in energy product of $\mathrm{Sm}-\mathrm{Co} / \mathrm{Mo} / \mathrm{Fe}$ exchange coupled samples by post annealing.

\section{EXPERIMENTAL PROCEDURE}

Series bilayers of $\mathrm{SmCo}_{5} / \mathrm{Fe}$ were fabricated with Mo interlayer between $\mathrm{SmCo}_{5}$ and $\mathrm{Fe}$ by magnetron sputtering on 70nm Cr buffered Si (100) substrate. Cr buffer layer was deposited at $650^{\circ} \mathrm{C}$ while all other layers were deposited at room temperature. The samples were annealed at $525^{\circ} \mathrm{C}$ for $30 \mathrm{~min}$ after deposition in the same chamber under high vacuum in $10^{-7}$ Torr range. The thickness of $\mathrm{SmCo}_{5}$ and $\mathrm{Fe}$ was fixed as $20 \mathrm{~nm}$. The nominal composition of the samples is

$\mathrm{Mo}(5 \mathrm{~nm}) / \mathrm{Fe}(20 \mathrm{~nm}) / \mathrm{Mo}(\mathrm{xnm}) / \mathrm{SmCo}_{5}(20 \mathrm{~nm}) /$

$\mathrm{Cr}(70 \mathrm{~nm}) / \mathrm{Si}(100)$

where $\mathrm{x}=0,0.3,0.5$ and 0.7 .

The base pressure during deposition was kept below $10^{-7}$ Torr. Ar pressure for depositing Fe, $\mathrm{Cr}$ and Mo was 3 mTorr while for $\mathrm{SmCo}_{5}$, Ar pressure was 5 mTorr. The substrate was kept rotating during deposition for getting uniform films. The deposition rate was measured by weight method. The deposition rate for $\mathrm{Fe}, \mathrm{Cr}$, Mo and $\mathrm{SmCo}_{5}$ was $0.325 \AA / \mathrm{sec}$ at $100 \mathrm{~W}, 0.204 \AA / \mathrm{sec}$ at $100 \mathrm{~W}, 0.308 / \mathrm{sec}$ at $100 \mathrm{~W}$ and 0.092 $\AA /$ sec at $130 \mathrm{~W}$ respectively.

\section{RESULTS AND DISCUSSIONS}

Fig. 1 shows the XRD pattern of $\mathrm{SmCo}_{5} / \mathrm{Fe}$ bilayers with $0.3 \mathrm{~nm}$ Mo interlayer between $\mathrm{Fe}$ and $\mathrm{SmCo}_{5}$. The pattern shows the presence of $\mathrm{Sm}_{2} \mathrm{Co}_{7}, \mathrm{SmCo}_{5}, \mathrm{Sm}_{2} \mathrm{Co}_{17}$ and $\mathrm{Fe}$ peaks. The appearance of different compositions of $\mathrm{SmCo}$ 
is due to the local variation of $\mathrm{Sm}$ and Co ratios from 1:5 ratio. The presence of $\mathrm{Sm}$ peak is attributed to the formation of Co rich phase of Sm-Co like $\mathrm{Sm}_{2} \mathrm{Co}_{17}$.

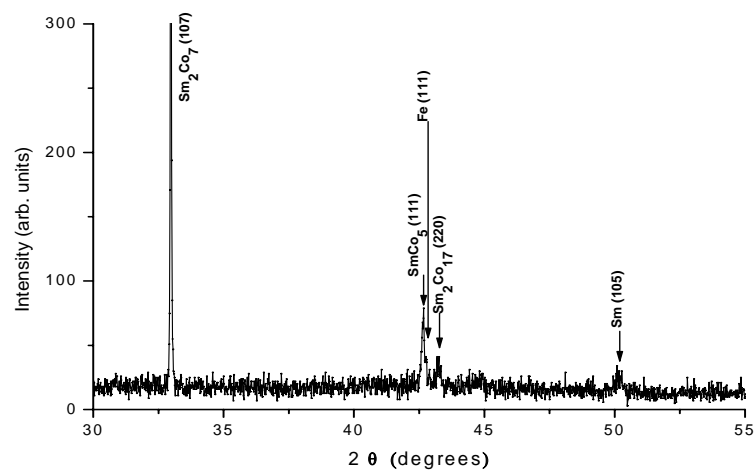

FIG. 1: XRD pattern of sample with composition $\mathrm{Mo}(5 \mathrm{~nm}) / \mathrm{Fe}(20 \mathrm{~nm}) / \mathrm{Mo}(0.3 \mathrm{~nm}) / \mathrm{SmCo}_{5}(20 \mathrm{~nm}) / \mathrm{Cr}(70 \mathrm{~nm}) \quad$ on $\mathrm{Si}$ (100) with $\mathrm{Cr}$ buffer layer deposited at $650^{\circ} \mathrm{C}$ and all other layers deposited at room temperature and annealed at $525^{\circ} \mathrm{C}$ for $30 \mathrm{~min}$.

Hysteresis loops of all of these samples showed strong exchange coupling between soft and hard phases and have single phase loops. Fig. 2 shows the hysteresis loop of the sample with Mo thickness as $0.3 \mathrm{~nm}$ between $\mathrm{Fe}$ and Sm-Co layers. The two phases switch together as a unit like single phase. When the soft and hard phases combined with each other are not exchange coupled with each other, there appears kink in second quadrant. On the other hand when the two magnetic phases are strongly coupled with each other, they show single phase loop. Next we present results of measurements of the retentivity magnetization $\mathrm{Mr}$, saturation magnetization Ms, coercivity $\mathrm{Hc}$, and energy product $(\mathrm{BH})_{\max }$.

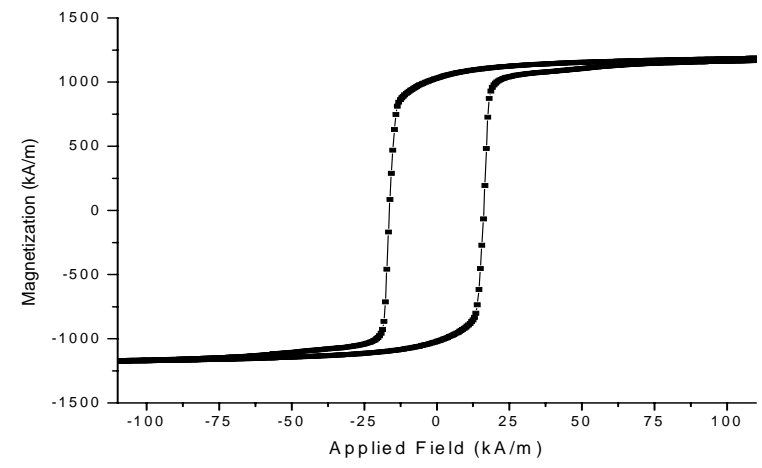

FIG. 2: Hysteresis loop of sample with composition Mo $\left.(5 \mathrm{~nm}) / \mathrm{Fe}(20 \mathrm{~nm}) / \mathrm{Mo}(0.3 \mathrm{~nm}) / \mathrm{SmCo}_{5}(20 \mathrm{~nm}) / \mathrm{Cr} 70 \mathrm{~nm}\right)$ on $\mathrm{Si}(100)$ with $\mathrm{Cr}$ buffer layer deposited at $650^{\circ} \mathrm{C}$ and all other layers deposited at room temperature and annealed at $525^{\circ} \mathrm{C}$ for $30 \mathrm{~min}$.

Fig. 3 shows the change in magnetization with variation of the Mo interlayer between the layers of $\mathrm{Fe}$ and $\mathrm{Sm}$ Co. The solid line is guide to eye. It is observed that the changes in magnetization with increasing interlayer thickness are sinusoidal-like. The description of such variation can be

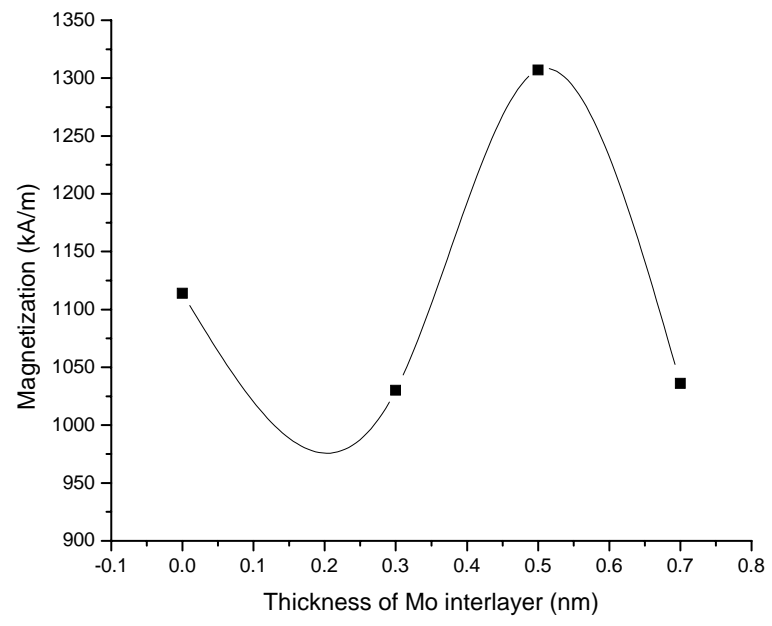

FIG. 3: Variation of magnetization $\mathrm{Mr}$ with thickness of Mo interlayer in $\mathrm{Fe}(20 \mathrm{~nm}) / \mathrm{Mo}(\mathrm{x} \mathrm{nm}) / \mathrm{SmCo}_{5}(20 \mathrm{~nm})$ with $\mathrm{x}=0,0.3,0.5 \&$ 0.7 , fabricated on $\mathrm{Cr}(70 \mathrm{~nm})$ buffered $\mathrm{Si}(100)$ substrate, deposited at room temperature and annealed at $525^{\circ} \mathrm{C}$ for $30 \mathrm{~min}$.

seen in ref. [12]. All of these samples have high magnetization. The reason of this higher value is $20 \mathrm{~nm}$ Fe layer thickness. Saturation magnetization behavior is similar to it as shown in Fig. 4. Saturation magnetizaton decreases from $1348 \mathrm{kA} / \mathrm{m}$ to $1217 \mathrm{kA} / \mathrm{m}$ then again rises up to $0.5 \mathrm{~nm} \mathrm{Mo}$ interlayer then it decreases again. The highest value of Ms found is as $1565 \mathrm{kA} / \mathrm{m} 0.5 \mathrm{~nm}$ Mo layer.

Variation of Coercivity with Mo interlayer is shown in Fig. 5. The coercivity first rises from $10.7 \mathrm{kA} / \mathrm{m}$ to $16.2 \mathrm{kA} / \mathrm{m}$ up to $0.3 \mathrm{~nm}$ Mo interlayer thickness then it falls for $0.5 \mathrm{~nm}$ thickness then there is again rising trend for $0.7 \mathrm{~nm}$ Mo layer. The behavior is sinusoidal-like.

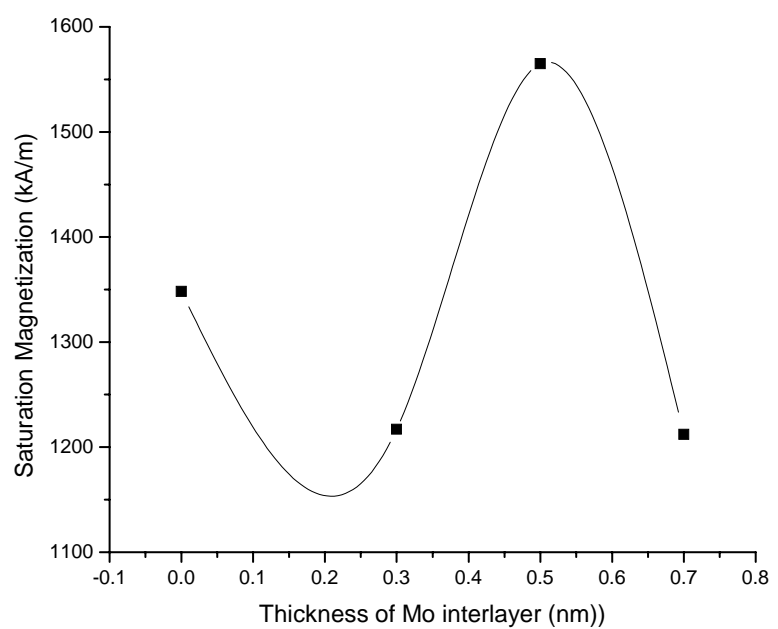

FIG. 4: Variation of saturation magnetization Ms with thickness of Mo interlayer in $\mathrm{Fe}(20 \mathrm{~nm}) / \mathrm{Mo}(\mathrm{x} \mathrm{nm}) / \mathrm{SmCo}_{5}(20 \mathrm{~nm})$ with $\mathrm{x}=0$, $0.3,0.5 \& 0.7$, fabricated on $\mathrm{Cr}(70 \mathrm{~nm})$ buffered $\mathrm{Si}$ (100) substrate, deposited at room temperature and annealed at $525^{\circ} \mathrm{C}$ for $30 \mathrm{~min}$. 


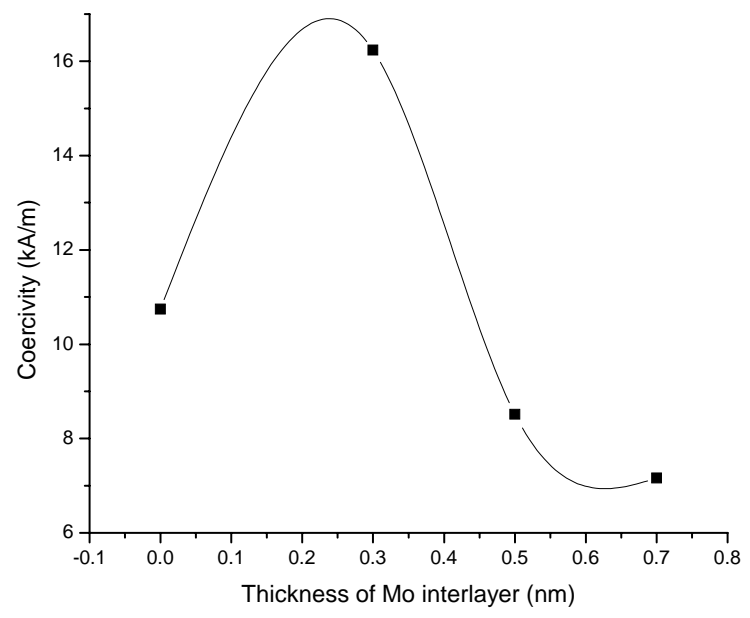

FIG. 5: Variation of coercivity Hc with thickness of Mo interlayer in $\mathrm{Fe}(20 \mathrm{~nm}) / \mathrm{Mo}(\mathrm{x} \mathrm{nm}) / \mathrm{SmCo}_{5}(20 \mathrm{~nm})$ with $\mathrm{x}=0,0.3,0.5 \& 0.7$, fabricated on $\mathrm{Cr}(70 \mathrm{~nm})$ buffered $\mathrm{Si}$ (100) substrate, deposited at room temperature and annealed at $525^{\circ} \mathrm{C}$ for $30 \mathrm{~min}$.

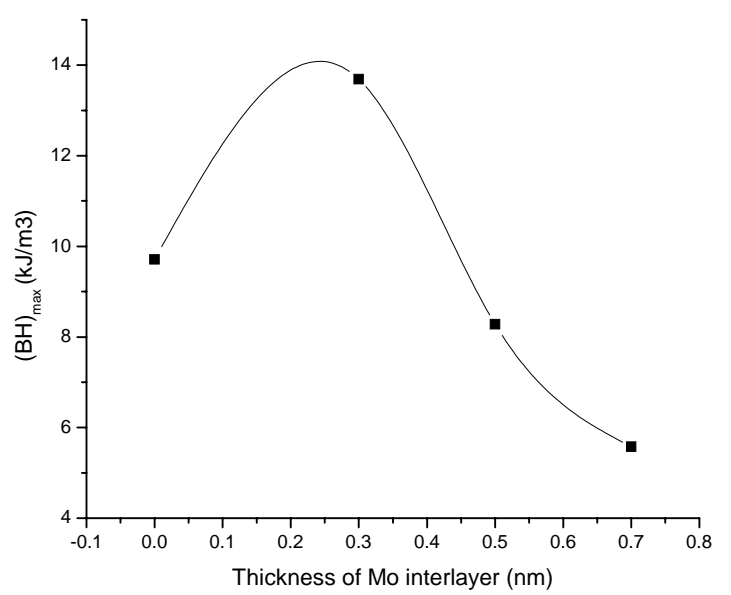

FIG. 6: Variation of energy product with thickness of Mo interlayer in $\mathrm{Fe}(20 \mathrm{~nm}) / \mathrm{Mo}(\mathrm{x} \mathrm{nm}) / \mathrm{SmCo}_{5}(20 \mathrm{~nm})$ with $\mathrm{x}=0,0.3,0.5 \& 0.7$, fabricated on $\mathrm{Cr}(70 \mathrm{~nm})$ buffered $\mathrm{Si}$ (100) substrate, deposited at room temperature and annealed at $525^{\circ} \mathrm{C}$ for $30 \mathrm{~min}$.
For energy product, $(\mathrm{BH})_{\max }$ variations with the Mo interlayer, there is enhancement in the $(\mathrm{BH})_{\max }$ value from $9.7 \mathrm{~kJ} / \mathrm{m}^{3}$ for sample without Mo interlayer to $13.7 \mathrm{~kJ} / \mathrm{m}^{3}$ for $0.3 \mathrm{~nm}$ Mo interlayer as shown in Fig. 6. However the optimized Mo layer from the trend of graph is between 0.2 to $0.3 \mathrm{~nm}$. It shows $(\mathrm{BH})_{\max }$ can be enhanced more by inserting Mo layer around $0.25 \mathrm{~nm}$. For further increasing Mo thickness from $0.3 \mathrm{~nm}$, there is again decrease in the energy product value. The rise noted is as $45 \%$ for the 0.3 $\mathrm{nm}$ Mo interlayer as compared to the sample without Mo interlayer. In another series, $\mathrm{Sm}-\mathrm{Co} / \mathrm{Mo} / \mathrm{Fe}$ were deposited at an elevated temperature and found some change in the above mentioned magnetic properties(not shown here) which shows that the magnetic properties in such combination of hard and soft phases also depends on the annealing conditions.

\section{Conclusion}

In conclusion, there is variation in the magnetic properties of the samples with the Mo interlayer between the layers of $\mathrm{Fe}$ and $\mathrm{Sm}-\mathrm{Co}$. The changes in magnetization and coercivity suggest a sinusoidal behavior. The optimum thickness of the Mo interlayer is around $0.3 \mathrm{~nm}$ for getting higher energy product. The rise in energy product is $45 \%$ as compared to the sample without Mo interlayer. Thus the Mo interlayer between $\mathrm{Fe}$ and Sm-Co layers is favorable for getting enhancement in energy product.
[1] A. M. Gabay, M. Marinescu and G. C. Hadjipanayis, Journal of Applied Physics 99, 08B506 (2006).

[2] J. Zhang, Y. K. Takahashi, R. Gopalan and K. Hono, Applied Physics Letters 86, 122509 (2005).

[3] J. Zhou, R. Skomski, Y. Liu, Y. C. Sui, W. Liu and D. J. Sellmyer. Journal of Applied Physics 97, 10K304 (2005).

[4] F. Shahzad, S. A. Siddiqi and J. Zhou, Chinese Physics Letters 26, 037701 (2009).

[5] E. F. Kneller and R. Hawig, IEEE Transactions on Magnetics 27, 3588 (1991).

[6] J. Ding, Y. Liu, R. Street, and P. G. McCormick, Journal of Applied Physics 75 (2), 1032 (1994).

[7] F. Yildiz, O. Yalcin, M. Ozdemir, B. Aktas, Y. Koseoglu, J. S. Jiang, Journal of Magnetism and Magnetic Materials 272-276, e1941 (2004).
[8] F. Shahzad, S. A. Siddiqi and J. Zhou, Chinese Physics Letters 25, 2642 (2008).

[9] Y. Hou, S. Sun, C. Rong and J. P. Liu, Applied Physics Letters 91, 153117 (2007).

[10] P. Grunberg, R. Schreiber, Y. Pang, M. B. Brodsky and C. H. Sowers, Physical Review Letters 57, 2442 (1986).

[11] S. S. P. Parkin, N. More and K. P. Roche, Physical Review Letters 64, 2304-2307 (1990).

[12] S. S. P. Parkin, Physical Review Letters 67, 3598 (1991).

[13] E. E. Fullerton, M. J. Conover, J. E. Mattson, C. H. Sowers and S. D. Bader, Physical Review B 48, 15755 (1993).

[14] J. Jiang, N. Tezuka and K. Inomata, Journal of Magnetism and Magnetic Materials 302, 40-46 (2006).

[15] F. Zhang, Z. Huang, Z. Lan, Z. Cui , J. Guo, W. Cheng and X. Yang, Journal of Rare Earths 26, 375 (2008). 